\title{
CICLO DE CONFERENCIAS SOBRE URBANISMO EN EL AYUNTAMIENTO DE SEVILLA
}

71

por

\section{Enrique Barrero González}

Durante los días 5 a 19 de noviembre de 1976 se desarrolló en el Ayuntamiento de Sevilla el III Ciclo de Conferencias de Urbanismo, que organiza la Alcaldía de dicho Ayuntamiento, por medio de su Gabinete de Estudios. Estos ciclos se vienen desarrollando desde 1974, con creciente éxito, dada la calidad de las personas que en ellos han venido interviniendo y la actualidad e importancia de los temas tratados.

La inauguración del Ciclo se realizó el día 5 de noviembre, bajo la presidencia, como es habitual, del Alcalde de la ciudad, don Fernando DE PARIAS MERRY, y asistencia de numerosas personas.

Pronunció la primera conferencia don José MARTín CRESPO, doctor Arquitecto, el cual disertó sobre «Influencia de la gestión urbanística en el planeamiento». Comenzó efectuando consideraciones generales sobre el planeamiento, insistiendo en la necesidad de huir de posiciones extremas, evitando tanto los planes utópicos 
e irreales, elaborados en laboratorios alejados de la realidad, como de planes que no tienen otro objeto que ajustarse a situaciones de hecho, plegándose a todo tipo de presiones. El Plan necesario - dijo- es aquel que es suficientemente bueno dentro de lo posible y realizable en cada circunstancia de lugar y tiempo. Estudió a continuación la nueva regulación que la Ley del Suelo hace del planeamiento, destacando sus cualidades fundamentales: la congruencia de los niveles de planeamiento general con el tamaño e importancia de la ciudad y la ruptura del principio de uniformidad, contemplando el Plan como una realidad flexible, mediante la distinción entre suelo urbanizable programado y no programado. Terminó haciendo extensas alusiones al tema del aprovechamiento medio, tema del que dijo que es eminentemente polémico y sujeto a precisiones reglamentarias aún no promulgadas.

Don Adolfo Carretero Pérez disertó el día 11 sobre "La expropiación urbanística en el Texto Refundido de la Ley del Suelo». El prestigioso Magistrado, especialista de lo Contencioso-administrativo en el Tribunal Supremo, centró su exposición en el estudio de las innovaciones más importantes que la Ley de 2 de mayo de 1975, de Reforma de la Ley sobre Régimen del Suelo y Ordenación urbana, había introducido en la Ley reformada de 12 de mayo de 1956, particularmente en toda la problemática relacionada con la institución de la expropiación forzosa.

Abordó con extensión el tema del ámbito de aplicación de los preceptos específicos dedicados a las valoraciones especiales que se establecen en la Ley para las expropiaciones por razón de urbanismo, exponiendo su interpretación de que el nuevo texto amplía dicho ámbito, para incluir actuaciones urbanísticas aisladas que anteriormente estaban excluidas del régimen de valoraciones especiales, y planteando los supuestos en que pudieran producirse dudas, y señalando criterios para resolverlas. Pasó al estudio del tema de las valoraciones previstas en la nueva legislación, destacando que ésta constituye un nuevo intento de establecimiento de valoraciones objetivas y glosando los diversos aspectos que contienen los preceptos en vigor.

Dedicó su atención, seguidamente, a la expropiación como sistema de ejecución de planes urbanísticos, destacando las diferencias existentes entre la antigua y la nueva regulación. 
Aludió a los cuatro tipos de expropiación que se regulan en la Ley: a la reparcelación como límite de la expropiación forzosa, a las cesiones obligatorias de suelo, a la reversión en materia de expropiaciones urbanísticas y a la modificación del derogado artículo 56 de la Ley del Suelo, que permitía la libre recuperación de las facultades dominicales de terrenos, afectados por los planes, en determinados supuestos.

Realizó, finalmente, una valoración de la reforma de la Ley del Suelo, destacando que esta nueva regulación supone, en el aspecto de las valoraciones de los bienes expresados, cierto sentido socializante de la propiedad, planteándose el interrogante de si se va a seguir en esta línea, corrigiendo las tendencias especulativas existentes, o se volverá a formas extremas de respeto de la privatización de la propiedad del suelo, que pudieran facilitar tales tendencias.

Don Martín Bassols Coma, Letrado de las Cortes Españolas, expuso el día 15 el tema "La disciplina urbanística».

Comenzó el conferenciante aludiendo a los temas capitales del Derecho urbanístico en la actualidad, entre los que destacó los del reconocimiento y extensión del derecho de propiedad y el correcto ejercicio de las facultades dominicales en el ámbito de la legalidad y planificación urbanísticas.

En este punto pasó a ocuparse específicamente del problema de la disciplina urbanística, entendida como adecuación del ejercicio de aquellas facultades a la normativa existente. La situación anterior a la reforma se caracterizaba por una acentuada indisciplina, que se manifestaba bien en una transgresión directa a los mandatos de la norma, bien en una inaplicación de los controles previstos en dicha norma o bien en una falta de redacción del aparato jurídico existente. Esto producía dos consecuencias importantes: daños a terceros y el daño social a la ciudad misma y a la colectividad.

Pasó a analizar los remedios que la Ley de 1975 ha arbitrado para luchar contra esta indisciplina mediante tres cauces. En primer lugar, la intervención de los Colegios profesionales, a través del visado, lo cual supone dar la entrada en este control a una corporación que no sólo debe velar por los derechos de sus miembros, sino que debe prestar un auténtico servicio público, previniendo posibles infracciones urbanísticas. 
En segundo lugar, la multiplicación de técnicas jurídicas para establecer la disciplina urbanística (suspensión de obras, suspen sión gubernativa de licencias, revisión de oficio de la licencia, acción popular, como cauce para su utilización por cualquier ciudadano contra la indisciplina urbanística, etc.).

En tercer lugar, un sistema de sanciones contra las transgresiones, cuya aportación esencial es un incremento cuantitativo. En este punto, el conferenciante se planteó el problema del delito urbanístico, afirmando que la Ley se ha quedado a medio camino, sin llegar a su tipificación.

Como conclusión, el señor Bassols afirmó que la Ley se ha sensibilizado en el tema, pero ha hecho una regulación deficiente, proponiendo medidas concretas, como la reorganización y coordinación de las inspecciones con cuadros técnicos eficientes. La concreción de fórmulas de controles políticos y administrativos superiores a los existentes, la sensibilización de la opinión pública y su canalización a través de asociaciones adecuadas y, en general, la democratización de la Administración municipal para propiciar una mayor intervención ciudadana en los asuntos públicos.

Don Manuel Delgado-IribarRen, Director del Centro de Estudios Urbanos, del Instituto de Estudios de Administración Local, desarrolló el día 17 su conferencia sobre «Extensión y contenido de la facultad de edificar atribuida a la propiedad del suelo».

Comenzó el conferenciante afirmando que a lo largo de este siglo se ha operado una profunda modificación del concepto de la propiedad, como consecuencia de los cambios ideológicos, políticos, sociales y económicos. La idea de limitación y de subordinación a la ley, que está presente en las definiciones más antiguas, ha estado oscurecida por la preponderancia del individualismo liberal del siglo XIX hasta fecha reciente. En la actualidad, el derecho de propiedad atribuye a su titular unas facultades muy concretas, que quedan muy lejos de ser todas las imaginables, según el concepto clásico, y que son distintas según el objeto a que se refieran. De ahí que resulte insuficiente la consideración puramente abstracta de la teoría clásica y sea necesario profundizar algo más en el contenido material del derecho atribuido a los propietarios.

A continuación pasó a examinar con extensión la facultad de edificar, que es característica de la propiedad del suelo y que está 
fuertemente condicionada por el ordenamiento jurídico, derivando de la concreta calificación legal del mismo.

Terminó haciendo extensa alusión a toda la problemática que plantea el tema de las licencias de edificación, en cuanto condicio. nan el ejercicio de la facultad de edificar.

El 19 de noviembre se celebró la clausura del Ciclo, que fue presidida por don Sebastián MARTf́n-Retortillo BaQUeR, Catedrático de Derechó administrativo y Subsecretario del Ministerio de Educación y Ciencia.

Comenzó el acto con unas palabras del Alcalde, señor PaRIAS, que hizo un resumen del Ciclo y de las finalidades que con el mismo se pretenden. A continuación don Manuel Clavero Arévalo, Ca tedrático de Derecho administrativo de la Universidad de Sevillá, efectuó la presentación del conferenciante, glosando sus cualidades humanas y profesionales.

El señor MAR'rín-ReToRtrillo desarrolló su conferencia comenzando con un estudio general de los sistemas de planificación urbanística. La Ley del Suelo de 1956 pretendió servir fielmente el esquema orgánico de nuestras entidades territoriales, distinguiendo los planes municipales, provinciales y nacionales. Se pretendía pasar de un urbanismo de ordenanza de edificación a un urbanismo de plan general de ordenación urbana.

La Ley de 1975 ha realizado una profunda reforma, considerando una nueva dimensión del urbanismo y creando el nuevo tipo de plan director, que implica una dimensión de ordenación del territorio, sin límite físico marcado, en íntima conexión con las previsiones de los planes de desarrollo.

A continuación pasó a examinar con profundidad el régimen jurídico de los planes directores territoriales de coordinación, deteniéndose en los aspectos de competencias, procedimientos de elaboración y aprobación de los mismos, contenido y efectos.

Abordó con posterioridad lo que denominó el conferenciante «mito y realidad de los planes directores territoriales de coordinación", aludiendo a que imponen una nueva metodología de trabajo, reforzando la idea de que el urbanismo ha de ser una ciencia interdisciplinaria, y terminó su conferencia haciendo extensa referencia a los problemas políticos con que estos planes se van a en. 
contrar en su desenvolvimiento. En primer lugar, el problema regional, manifestándose partidario de que las Regiones recaben para sí la competencia de tan importante instrumento. En segundo lugar, a la imperiosa y obligada necesidad de que, a través de los planes directores, se coordinen los planes sectoriales y los objetivos de las políticas de los distintos Ministerios. 
REVL-1977, núm. 193. BARRERO GONZALEZ, ENRIQUE. CICLO DE CONFERENCIAS SOBRE URBA...

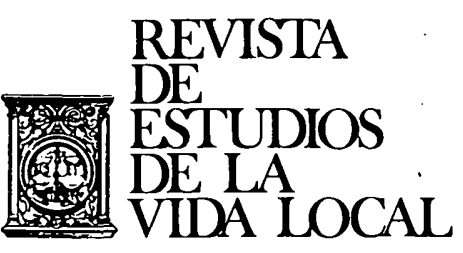

\section{ESTADISTICA}


REVL-1977, núm. 193. BARRERO GONZALEZ, ENRIQUE. CICLO DE CONFERENCIAS SOBRE URBA...

REVL-1977, núm. 193. BARRERO GONZALEZ, ENRIQUE. CICLO DE CONFERENCIAS SOBRE URBA... 